\title{
Intrathecally administered ropivacaine is less neurotoxic than procaine, bupivacaine, and levobupivacaine in a rat spinal model
}

\section{La ropivacaïne administrée par voie intrathécale est moins neurotoxique que la procaïne, la bupivacaïne et la lévobupivacaïne dans un modèle médullaire de rat}

\author{
Tamie Takenami, MD • Guoqin Wang, MD, PhD • \\ Yoshihiro Nara, DVM • Sayano Fukushima, MD, PhD • \\ Saburo Yagishita, MD, PhD • Hiromi Hiruma, MD, PhD • \\ Tadashi Kawakami, MD, PhD • Hirotsugu Okamoto, MD, PhD
}

Received: 29 December 2010/ Accepted: 15 February 2012/Published online: 2 March 2012

(C) Canadian Anesthesiologists' Society 2012

\begin{abstract}
Purpose The aim of this study was to compare the neurotoxicity of intrathecal procaine, bupivacaine, levobupivacaine, and ropivacaine in an animal model.

Methods The study comprised two experiments. In the concentration experiment, rats $(n=78)$ were administered $0.12 \mu \mathrm{L} \cdot \mathrm{g}^{-1}$ body weight (BW) of $2 \%$ or $20 \%$ procaine, $0.5 \%$ or $5 \%$ bupivacaine, $0.5 \%$ or $5 \%$ levobupivacaine, or $0.5 \%$ or $5 \%$ ropivacaine. Based on the findings, the doses
\end{abstract}

\begin{abstract}
Author contributions Tamie Takenami designed and initiated this study, took part in all aspects of the experiments, collected data for statistical analysis, and wrote the manuscript. Guoqin Wang performed statistical tests, assisted with the statistical analysis, and proposed the method of statistical analysis to validate the injury score. Yoshihiro Nara assisted with catheterization, drug injection, and securing the catheters. He also performed evaluations for the ambulation and paw stimulation tests. Sayano Fukushima assisted with the assessment of the injury scores. Saburo Yagishita verified the pathological changes. Hiromi Hiruma and Tadashi Kawakami allowed use of their laboratory during the study and reviewed the manuscript. Hiromi Hiruma, Tadashi Kawakami, and Hirotsugu Okamoto offered their advice.
\end{abstract}

T. Takenami, MD $(\bowtie) \cdot$ Y. Nara, DVM $\cdot$ S. Fukushima, MD, $\mathrm{PhD} \cdot \mathrm{H}$. Okamoto, MD, $\mathrm{PhD}$

Department of Anesthesiology, Kitasato Clinical Research

Center, Kitasato University School of Medicine,

1-15-1 Kitasato, Sagamihara, Kanagawa 228-8555,

Japan

e-mail: takenami@med.kitasato-u.ac.jp

H. Hiruma, MD, PhD - T. Kawakami, MD, PhD

Department of Physiology, Kitasato Clinical Research Center, Kitasato University School of Medicine, Sagamihara,

Kanagawa, Japan were increased by volume in the subsequent volume experiment using 0.12, 0.24, or $0.48 \mu \mathrm{L} \cdot \mathrm{g}^{-1} \mathrm{BW}$ of $6 \%$ procaine, $6 \%$ levobupivacaine, or $6 \%$ ropivacaine $(n=79)$. Walking behaviour and sensory threshold were analyzed, and a histological examination of the spinal cord, posterior and anterior roots, and cauda equina was performed.

Results The concentration experiment showed abnormalities only in the 5\% bupivacaine group, and these abnormal findings were in the posterior root $(P R)$ and posterior column (PC). The volume experiment revealed that procaine $0.24 \mu \mathrm{L} \cdot \mathrm{g}^{-1}$ was neurotoxic, mainly affecting the PR. At $0.48 \mu L \cdot \mathrm{g}^{-1}$, severe injury was observed in the $P R$ and $P C$ in all six procaine rats and four of six levobupivacaine rats, while milder injury was limited to the $P R$ in one of six ropivacaine rats, which differed significantly from the former two groups $(P=0.006$ and $P=0.014$, respectively). Electron microscopy showed axonal degeneration.

Conclusion All four local anesthetics seemed to cause identical neurotoxic lesions commencing in the PR and

G. Wang, MD, PhD

Department of Community-Based Perinatal and Emergency

Medicine, Kitasato Clinical Research Center,

Kitasato University School of Medicine, Sagamihara,

Kanagawa, Japan

S. Yagishita, MD, PhD

Department of Pathology, Kanagawa Rehabilitation Center, Atsugi, Kanagawa, Japan 
extending to the PC by axonal degeneration. Bupivacaine appeared to be the most neurotoxic of the four drugs, and the neurotoxicity at higher doses increased by volume with procaine $>$ levobupivacaine $>$ ropivacaine.

\section{Résumé}

Objectif L'objectif de cette étude était de comparer la neurotoxicité intrathécale de la procaine, de la bupivacaïne, de la lévobupivacaïne et de la ropivacaïne dans un modèle animal.

Méthodes L'étude a comporté deux expérimentations. Dans une expérience sur la concentration, des rats $(n=78)$ ont reçu $0,12 \mu \mathrm{L} \cdot \mathrm{g}^{-1}$ de poids corporel de procaïne à $2 \%$ ou $20 \%$, de bupivacaïne à $0,5 \%$ ou $5 \%$, de lévobupivacaïne à $0,5 \%$ ou $5 \%$ ou de ropivacaine à $0,5 \%$ ou $5 \%$. Selon les constatations effectuées, les volumes des doses ont été augmentées dans l'expérience suivante sur les volumes avec des doses de 0,12, 0,24 ou $0,48 \mu \mathrm{L} \cdot \mathrm{g}^{-1}$ de poids corporel de procaine à $6 \%$, de lévobupivacaïne à $6 \%$ ou de ropivacaïne à $6 \%(n=79)$. Le comportement à la marche et le seuil de sensibilité ont été analysés, puis un examen histologique de la moelle épinière, des racines antérieures et postérieures, et de la queue de cheval a été réalisé.

Résultats L'expérience sur la concentration n'a mis en évidence des anomalies que dans le groupe bupivacaïne 5\% et ces constatations anormales concernaient la racine postérieure et la colonne postérieure. L'expérience sur les volumes a révelé que la procaïne à la dose de $0,24 \mu \mathrm{L} \cdot \mathrm{g}^{-1}$ était neurotoxique, affectant principalement la racine postérieure. À $0,48 \mu \mathrm{L} \cdot \mathrm{g}^{-1}$, une lésion sévère de la racine postérieure et de la colonne postérieure a été observée chez les six rats ayant reçu de la procaïe et chez quatre des six rats ayant reçu de la levobupivacaïne; une lésion moins sévère a été constatée sur la racine postérieure de l'un des six rats sous ropivacaïne, ce qui était significativement différent des deux groupes précédents (respectivement, $P=0,006$ et $P=0,014)$. L'examen en microscopie électronique a montré une dégénérescence axonale.

Conclusion Les quatre anesthésiques locaux semblent provoquer des lésions neurotoxiques identiques débutant dans la racine postérieure et s'étendant à la colonne postérieure par dégénérescence axonale. La bupivacaine paraît être le plus neurotoxique des quatre médicaments et la neurotoxicité; à des concentrations élevées la toxicité augmente avec le volume injecté avec la procaïne $>$ lévobupivacaïne $>$ ropivacaïne.

In 1979, Albright's report ${ }^{1}$ on fatal cardiotoxicity induced by a racemic bupivacaine mixture of $\mathrm{S}(-)$ and $\mathrm{R}(+)$ enantiomers triggered efforts to find less toxic local anesthetics. Consequently, ropivacaine and levobupivacaine, both of which are pure $\mathrm{S}(-)$ enantiomers, were developed because of their stereoselectivity and low cardiotoxicity. ${ }^{2,3}$ Later studies confirmed that both agents are less toxic than racemic bupivacaine and $\mathrm{R}(+)$ bupivacaine for the central nervous and cardiovascular systems in animals ${ }^{4,5}$ and humans. $^{6-8}$

In a series of studies, we determined the neurotoxicities of lidocaine, tetracaine, bupivacaine, mepivacaine, prilocaine, and procaine $e^{9-12}$ in a rat spinal model. These studies showed that all these agents, with the exception of procaine, were neurotoxic, with lesions displaying common features irrespective of the anesthetic agent and affecting mainly axons of the dorsal root entry zone. Procaine was not neurotoxic even at ten times (20\%) the clinical concentration. $^{12}$

We consider it important to base the ranking of local anesthetic toxicity on the severity and location of damage because: 1) laboratory information may be useful in predicting which local anesthetics can be employed safely in the clinical setting with minimal side effects; and 2) identifying the lesions that are typical of local anesthetic toxicity could help to determine neurological signs of toxicity and the differential diagnosis between anestheticinduced toxicity and other causes of postoperative neuropathy. The present work is an extension of our previous studies. Its main purpose is to identify potentially safer drugs by further ranking the potential toxicity of S-form levobupivacaine and ropivacaine compared with the previously investigated procaine. The study was conducted in the same rat model, which was assessed both neurofunctionally and histologically.

\section{Methods}

The Ethics Committee on Animal Research of Kitasato University School of Medicine approved the study protocol. Experiments were conducted on 157 male Wistar rats (12-wk-old; body weight [BW], 264-330 g). The study consisted of two experiments. The concentration experiment was performed to confirm that procaine, levobupivacaine, and ropivacaine were less neurotoxic than bupivacaine at doses in the clinical range. The subsequent volume experiment was performed to identify the least neurotoxic drug among procaine, levobupivacaine, and ropivacaine by using greater than clinical doses.

The pharmacological potency ratio for procaine: bupivacaine: levobupivacaine: ropivacaine is considered to be 0.25 : 1: 1 : 1 , based on previous animal data ${ }^{13,14}$ and common clinical practice (equivalent clinical concentrations are $2 \%$ for procaine and $0.5 \%$ for bupivacaine, levobupivacaine, and ropivacaine). ${ }^{15,16}$ 
Surgical procedure for intrathecal catheterization

The rats were anesthetized by inhalation of isoflurane. The subarachnoid space was cannulated using a polyethylene tube $(0.6 \times 700 \mathrm{~mm})$ advanced through the atlantooccipital membrane using the modified method of Yaksh and Rudy. ${ }^{17}$ The tip of the catheter was advanced $8 \mathrm{~cm}$ caudal to the L3 level. The other end of the catheter was fixed in the subcutaneous tissue to avoid displacement. The rats were allowed to recover fully, and the test drug was injected one week after the catheterization procedure. Rats showing symptoms of traumatic nerve damage were excluded from the study.

Intrathecal administration of anesthetic agents

On day seven after intrathecal catheterization, each rat received the test drugs via the catheter. In the concentration experiment, the clinical concentration or ten times that concentration was used ( $2 \%$ or $20 \%$ procaine, $0.5 \%$ or $5 \%$ bupivacaine, $0.5 \%$ or $5 \%$ levobupivacaine, $0.5 \%$ or 5\% ropivacaine [Astra Zeneca, Tokyo, Japan]). The total volume of injection was $0.12 \mu \mathrm{L} \cdot \mathrm{g}^{-1} \mathrm{BW}$ plus $6 \mu \mathrm{L}$ for the dead space of the catheter. In the volume experiment, rats were injected $0.12,0.24$, or $0.48 \mu \mathrm{L} \cdot \mathrm{g}^{-1}$ BW (plus $6 \mu \mathrm{L}$ for the dead space of the catheter) of $6 \%$ procaine, levobupivacaine, or ropivacaine. Each drug was dissolved in distilled water. In each experiment, the control solution was distilled water of the same volume as the test drug. Each solution was prepared under aseptic conditions on the morning of the day of injection. Drug administration was performed under isoflurane inhalation delivered through a face-snout mask. The skin was opened to expose the subcutaneously embedded catheter, and then each solution was administered manually through the catheter over a 15 -sec period. Immediately after drug injection, isoflurane inhalation was stopped (total inhalation time, $<$ five minutes) and the wound was sutured leaving the catheter under the skin. The rats were allowed to breathe room air until recovery from anesthesia.

Neurofunctional tests

\section{Recovery time to ambulation}

Each rat was evaluated behaviourally for the ability to walk with or without limitation. Evaluations were conducted at $0.25,0.5$, one, two, three, and four hours after intrathecal injection of the drug on the day of injection (post-injection day [PID] 0) and every morning from the next day (PID1) until PID4. The recovery time to normal ambulation was recorded in the concentration experiment. In the volume experiment, some rats did not recover to normal ambulation even at PID4. Therefore, hind limb movement was scored from PID0 to PID4 in the later experiment: score $0=$ normal walking (walk briskly without slipping or dragging limbs), score $1=$ walk with limitation, score $2=$ unable to walk. Estimation of walking behaviour was performed by an experimenter (Y.N.) who was unaware of the group.

\section{Paw stimulation test}

The latency of the hind limb withdrawal response to radiant heat delivered on the plantar surface was measured before injection of the drug (pre-latency) and on PID4 (postlatency) only in the volume experiment. For each rat, measurements were repeated six times on both the left and right paws. The data were converted to percent maximum possible effect (\%MPE), calculated as ([post-latency - pre-latency]/[cut-off time - pre-latency] $\times 100$ ). The cut-off time was fixed at $20 \mathrm{sec}$ to prevent thermal injury. Estimation of latency to radiant heat was performed by an experimenter (Y.N.) unaware of the group.

\section{Tissue preparation}

At PID4 and following completion of the above two functional tests, the rats were deeply anesthetized and perfused transcardially with fixative $(2.5 \%$ cacodylatebuffered glutaraldehyde) for histological examination. The lumbar spinal cord with the anterior and posterior roots and the cauda equina were removed en bloc from the fixed animals and dissected into four samples: transverse section with both roots, both roots just proximal to the dorsal ganglion, and cauda equina nerves. These samples were then prepared for light and electron microscopy, as described in our previous studies. ${ }^{9-12}$ Briefly, all specimens were embedded in epoxy resin. The spinal cord at L3 was divided into two parts. After embedding the two parts in resin as a block, each block was sliced into four sections, and the slice showing the most severe injury was used for histological analysis. Semi-thin sections $(0.5-1.0 \mu \mathrm{m}$ thick) were prepared and stained with polychrome dyes for light microscopy, while ultrathin resin sections (70-80 nm thick) were doublestained with uranyl acetate and lead citrate for examination under a JOEL FX2000 electron microscope (Nippon Denshi, Tokyo) at $100 \mathrm{keV}$.

Histological abnormality represented a lesion containing infiltrated macrophages with destruction of the myelin sheaths and/or axons. The distribution and severity of each lesion were analyzed. The distribution of the lesion, Distribution (D)-Score, was graded score $1=$ lesions limited to the posterior root (PR), and score $4=$ lesions observed 
in both the PR and posterior column (PC). The severity of the lesion affecting the PR and PC, Severity (S)-Score, was also classified into score $0=$ no lesion; score $1=$ mild lesion (focal disruption of myelin sheath and axons); score $2=$ moderate lesion; and score $3=$ severe lesion (diffuse disruption of myelin sheath and axons). The sum of the D-score plus the S-score for the PR and the S-score for the PC was considered the injury score. Within-observer and between-observer reliability were estimated in a pilot study. The results showed the high reliability of this assessment method, with Spearman correlation coefficients of 0.767 and 0.969 for results within observers $\mathrm{A}$ and $\mathrm{B}$ and 0.814 for results between observers A and B. In the present study, two experienced investigators assessed all specimens independently, and variant cases were reviewed and discussed until a consensus was reached.

\section{Statistical analysis}

Continuous variables are presented as median (range), while numerical variables are presented as numbers (\%). To detect significance among different drug groups with respect to recovery time, injury score, and \%MPE values, the Kruskal-Wallis test was used to determine the global $P$ value, and a Bonferroni post-hoc test was used to determine a pairwise statistical significance. The Fisher's exact test was applied to evaluate the difference in the incidences of pathological lesions among the different drug groups. For the volume experiment, changes in behaviour scores with time among the drug injection groups were tested by the General Linear Model for repeated measures. We used the injury score to represent the main outcome and to determine the appropriate sample size. Five rats per group were needed for a difference of 4 in the severity score of any two drug groups with a standard deviation of 2 , and for a power of $80 \%$ at alpha level of 0.05 . Instead, we used seven rats in each group to avoid any unexpected events during the study. The conventional $P$ value of 0.05 or less was used to detect statistical significance. All reported $P$ values are two sided. Analyses were performed independently at Kitasato Clinical Research Center using the SPSS $^{\circledR}$ software version 17.0 (SPSS Inc., Chicago, IL, USA).

\section{Results}

The concentration experiment

Eight rats were excluded from the study because of hind limb palsy caused by traumatic injury (three rats), subarachnoiditis due to catheterization (four rats), and epidural insertion (one rat). The remaining 70 rats were divided into the control group (distilled water, $n=6$ ), procaine groups ( $2 \%, n=8 ; 20 \%, n=8)$, bupivacaine, levobupivacaine, and ropivacaine groups $(0.5 \%, n=8$ for each drug; $5 \%$, $n=8$ for each drug).

Neurofunctional deficits

\section{Recovery time to ambulation}

Control animals showed complete recovery within 15 min after intrathecal injection. In all drug groups, higher concentrations produced longer anesthesia. When ten times the clinical concentration was used, the recovery time for each drug was longer than with the clinical concentration $(P<0.001$, Table 1$)$. Rats that received $2 \%$ and $20 \%$ procaine showed significantly faster recovery compared with those injected with equivalent pharmacological concentrations of other drugs. There were no significant differences among bupivacaine, levobupivacaine, and ropivacaine at each concentration.

\section{Histopathological assessment of neurotoxicity}

Histological abnormalities were observed only in three of eight rats injected with $5 \%$ bupivacaine (all showed lesions in both PR and PC, with an injury score of 6,6 , and 7 , respectively) ( $P=0.045$ among drug groups). None of the other groups showed pathological abnormalities. The pathological lesions induced by bupivacaine were limited to the proximal portion of the PR just adjacent to the PC (entry zone) and the fasciculus cuneatus (FC) on the lateral side of the PC. No lesions were noted in other areas, including the peripheral portion of the PR just above the dorsal ganglion.

Table 1 Time (hr) to recovery to normal ambulation (score 0 ) in the concentration experiment

\begin{tabular}{lclll}
\hline & 1 Time & $P$ value & 10 Times & $P$ value \\
\hline Procaine & $0.5(0.25-0.5)$ & & $1(0.5-1)$ & \\
Bupivacaine & $1(1-1)$ & $<0.001^{*}$ & $4(2-4)$ & $<0.001^{*}$ \\
Levobupivacaine & $1(0.5-1)$ & $<0.03^{*}$ & $4(2-4)$ & $<0.001^{*}$ \\
Ropivacaine & $1(0.5-1)$ & $<0.03^{*}$ & $4(2-4)$ & $<0.001^{*}$ \\
\hline
\end{tabular}

Data are expressed as median (minimum - maximum). $n=8$ for each group

1 time = clinical concentration: $2 \%$ for procaine, $0.5 \%$ for bupivacaine, levobupivacaine, and ropivacaine; 10 times $=10$ times the clinical concentration: $20 \%$ for procaine, $5 \%$ for bupivacaine, levobupivacaine, and ropivacaine. Time to recovery was longer with 10 times the concentration for each local anesthetic $(P<0.001)$ (KruskalWallis $\mathrm{H}$ test)

* Between bupivacaine, levobupivacaine, and ropivacaine $v s$ procaine (Bonferroni post-hoc test, Mann-Whitney U test) 


\section{The volume experiment}

Nine rats were excluded from the study due to hind limb palsy caused by traumatic injury (five rats) and subarachnoiditis associated with catheterization (four rats). Each of the remaining 70 rats was injected with one of three volumes: $0.12,0.24$, or $0.48 \mu \mathrm{L} \cdot \mathrm{g}^{-1} \mathrm{BW}$ of distilled water, $6 \%$ procaine, levobupivacaine, or ropivacaine. The number of rats in each group was as follows: $0.12 \mu \mathrm{L} \cdot \mathrm{g}^{-1}$ distilled water ( $n=5,0.12$ control group), $0.12 \mu \mathrm{L} \cdot \mathrm{g}^{-1}$ of procaine, levobupivacaine, ropivacaine $(n=6$, respectively); 0.24 $\mu \mathrm{L} \cdot \mathrm{g}^{-1}$ distilled water $(n=5,0.24$ control group), $0.24 \mu \mathrm{L} \cdot \mathrm{g}^{-1}$ of procaine $(n=6)$, levobupivacaine $(n=7)$, ropivacaine $(n=6) ; 0.48 \mu \mathrm{L} \cdot \mathrm{g}^{-1}$ distilled water $(n=5$, 0.48 control group), $0.48 \mu \mathrm{L} \cdot \mathrm{g}^{-1}$ of procaine, levobupivacaine, ropivacaine ( $n=6$, respectively).

Neurofunctional deficits

\section{Recovery time to ambulation}

Table 2 and Fig. 1 display the changes in behaviour scores for different drug groups and show significant differences among drugs at each dose $(P<0.001$, respectively). The behaviour score of the $0.12 \mu \mathrm{L} \cdot \mathrm{g}^{-1}$ procaine group was significantly lower than the behaviour scores of the $0.12 \mu \mathrm{L} \cdot \mathrm{g}^{-1}$ levobupivacaine $(P<0.001)$ and $0.12 \mu \mathrm{L} \cdot \mathrm{g}^{-1}$ ropivacaine groups $(P=0.001)$. However, the behaviour scores of rats injected with procaine worsened with the increase in volume, and the $0.48 \mu \mathrm{L} \cdot \mathrm{g}^{-1}$ procaine group recovered significantly slower than the $0.48 \mu \mathrm{L} \cdot \mathrm{g}^{-1}$ ropivacaine group (Table 2). Only rats administered with ropivacaine did not show hind limb palsy even at a volume of $0.48 \mu \mathrm{L} \cdot \mathrm{g}^{-1}$.

\section{Paw stimulation test}

Fig. 2 shows the effects of anesthetic agents on the sensory threshold expressed as \%MPE. The $0.48 \mu \mathrm{L} \cdot \mathrm{g}^{-1}$ procaine group tended to have a higher threshold, although there was no significant difference among the three drug groups.

\section{Histopathological assessment of neurotoxicity}

Table 3 provides a summary of the injury scores of the different groups. No histological changes were observed in all drug groups at the $0.12 \mu \mathrm{L} \cdot \mathrm{g}^{-1}$ level. At the $0.24 \mu \mathrm{L} \cdot \mathrm{g}^{-1}$ level, injury was observed in only three of six rats given procaine (two rats in the PR, one rat in the PR and FC), with injury scores of 6,6 , and 8 , respectively. At the $0.48 \mu \mathrm{L} \cdot \mathrm{g}^{-1}$ level, injury was observed in all six rats administered procaine (all in the PR and FC), with all injury scores being 10; four of six rats given levobupivacaine (all in the PC and FC), with injury scores of 8, 8, 9, and 10, respectively; and one of six rats injected with ropivacaine (only in the $\mathrm{PR}$ ) with an injury score of 1 . The incidences of histological lesions $(P=0.034)$ and injury scores $(P=0.001)$ were significantly different between the drugs only at the $0.48 \mu \mathrm{L} \cdot \mathrm{g}^{-1}$ level. At this dose level, the incidence of lesions was higher in the procaine group than in the ropivacaine group $(P=0.029)$; procaine and levobupivacaine induced significantly higher injury scores compared with control $(P=0.008$ and $P=0.007$, respectively) or ropivacaine $(P=0.006$ and $P=0.014$, respectively), but no difference was observed between procaine and levobupivacaine $(P=0.243)$.

All pathological lesions were limited to the proximal PR portion (entry zone) or FC of the PC, as confirmed by light microscopy (Fig. 3), while other areas, such as the dorsal horn, anterior horn, and anterior root were intact. In the

Table 2 Behaviour score for each drug group in the volume experiment

\begin{tabular}{|c|c|c|c|c|c|c|c|c|c|c|c|c|}
\hline \multirow[t]{2}{*}{ Group } & \multirow[t]{2}{*}{ Drug } & \multicolumn{10}{|c|}{ Time after injection (hours) } & \multirow[t]{2}{*}{$P$ value } \\
\hline & & 0 & 0.5 & 1 & 2 & 3 & 4 & 24 & 48 & 72 & 96 & \\
\hline \multirow[t]{3}{*}{$0.12 \mu \mathrm{L} \cdot \mathrm{g}^{-1}$} & procaine & $2(2-2)$ & $0.5(0-2)$ & 0 & 0 & 0 & 0 & 0 & 0 & 0 & 0 & \multirow[t]{3}{*}{$<0.001$} \\
\hline & levobupivacaine & $2(2-2)$ & $2(2-2)$ & $2(2-2)$ & $2(2-2)$ & $2(2-2)$ & $1(0-2)$ & $0(0-1)$ & 0 & 0 & 0 & \\
\hline & ropivacaine* & $2(2-2)$ & $2(2-2)$ & $2(2-2)$ & $1(0-2)$ & $0(0-2)$ & $0(0-2)$ & 0 & 0 & 0 & 0 & \\
\hline \multirow[t]{3}{*}{$0.24 \mu \mathrm{L} \cdot \mathrm{g}^{-1}$} & procaine & $2(2-2)$ & $1(0-2)$ & $0(0-1)$ & 0 & 0 & 0 & 0 & 0 & 0 & 0 & \multirow[t]{3}{*}{$<0.001$} \\
\hline & levobupivacaine & $2(2-2)$ & $2(2-2)$ & $2(2-2)$ & $2(2-2)$ & $2(1-2)$ & $2(0-2)$ & 0 & 0 & 0 & 0 & \\
\hline & ropivacaine* & $2(2-2)$ & $2(2-2)$ & $2(2-2)$ & $1(0-2)$ & $0.5(0-2)$ & $0.5(0-2)$ & 0 & 0 & 0 & 0 & \\
\hline \multirow[t]{3}{*}{$0.48 \mu \mathrm{L} \cdot \mathrm{g}^{-1}$} & procaine & $2(2-2)$ & $2(2-2)$ & $2(2-2)$ & $2(2-2)$ & $1.5(1-2)$ & $1(1-2)$ & $1(1-2)$ & $1(0-2)$ & $1(0-2)$ & $0.5(0-2)$ & \multirow{3}{*}{$<0.001$} \\
\hline & levobupivacaine & $2(2-2)$ & $2(2-2)$ & $2(2-2)$ & $2(2-2)$ & $2(1-2)$ & $2(0-2)$ & $1(0-2)$ & $1(0-2)$ & $0.5(0-1)$ & $0.5(0-1)$ & \\
\hline & ropivacaine* & $2(2-2)$ & $2(2-2)$ & $2(2-2)$ & $2(2-2)$ & $1.5(1-2)$ & $0.5(0-2)$ & $0^{\top}$ & $0^{\top}$ & 0 & 0 & \\
\hline
\end{tabular}

Data are presented as median behaviour score (range). $\dagger$ Changes in behaviour scores among the drug groups were significantly different at each volume (by general linear model for repeated measures). $\uparrow=P<0.05$ procaine $v$ s levobupivacaine and ropivacaine at $0.12 \mu \mathrm{L} \cdot \mathrm{g}^{-1}$ and ropivacaine at $0.24 \mu \mathrm{L} \cdot \mathrm{g}^{-1} ; *=P<0.05$ compared with levobupivacaine 

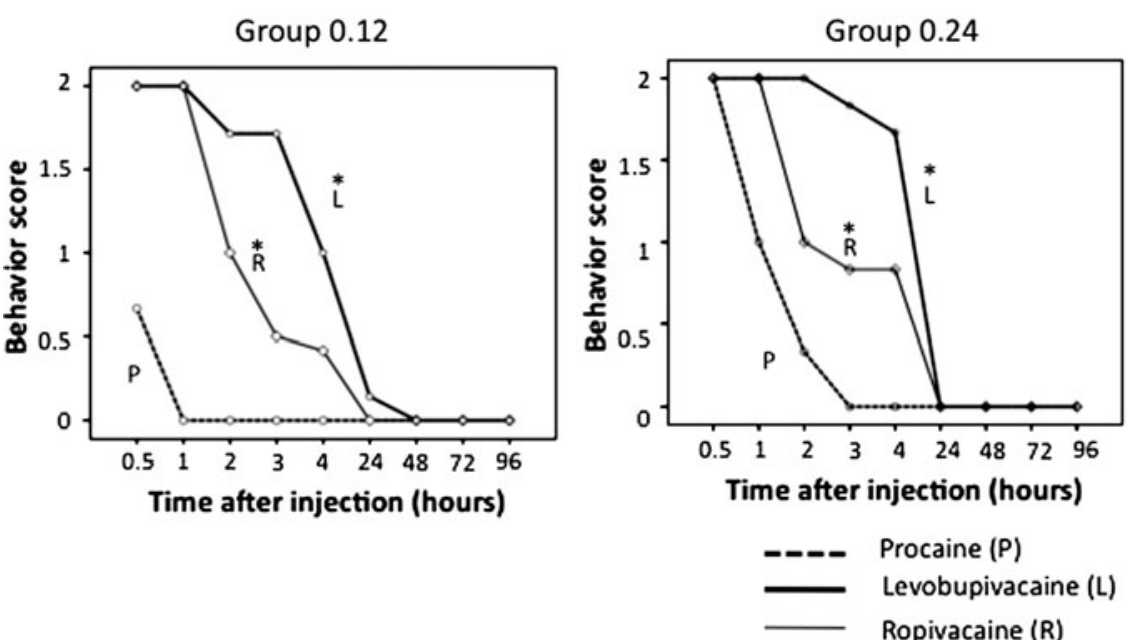

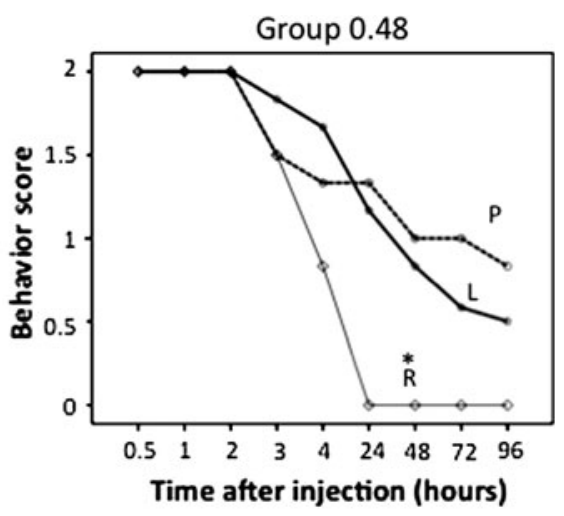

Fig. 1 Changes in behaviour scores in the procaine $(\mathrm{P})$, ropivacaine (R) and levobupivacaine $(\mathrm{L})$ groups in the volume experiment. The volume in $\mu \mathrm{L} \cdot \mathrm{g}^{-1}$ is indicated at the top of each graph. ${ }^{*} P$ indicates $<0.05$ difference $v s$ the procaine group. Behaviour scores at each drug concentration were different among the drug groups. The mean behaviour score of rats that received procaine at $0.12 \mu \mathrm{L} \cdot \mathrm{g}^{-1}$ body weight (BW) (A) was lower than that of rats that received ropivacaine and levobupivacaine at $30 \mathrm{~min}$ after injection. At $0.12 \mu \mathrm{L} \cdot \mathrm{g}^{-1} \mathrm{BW}$ (A) and $0.24 \mu \mathrm{L} \cdot \mathrm{g}^{-1} \mathrm{BW}$ (B) levels, the procaine

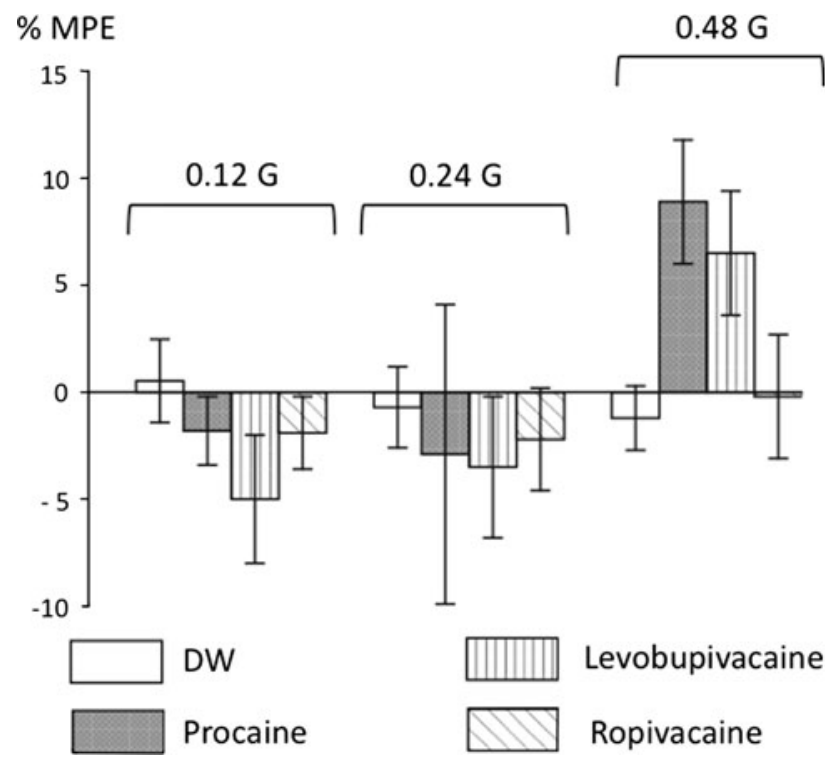

Fig. 2 Paw stimulation test in the volume experiment expressed as a percent change in maximum possible effect (\%MPE). Data are expressed as median [interquartile range]. There were no significant differences in \%MPE values between the three groups at $0.12 \mu \mathrm{L} \cdot \mathrm{g}^{-1}$ body weight $(\mathrm{BW})(P=0.954), 0.24 \mu \mathrm{L} \cdot \mathrm{g}^{-1} \mathrm{BW}(P=0.582)$, and $0.48 \mu \mathrm{L} \cdot \mathrm{g}^{-1} \mathrm{BW}(P=0.069)$. DW $=$ distilled water

$0.24 \mu \mathrm{L} \cdot \mathrm{g}^{-1}$ procaine (Fig. 3B) and $0.48 \mu \mathrm{L} \cdot \mathrm{g}^{-1}$ ropivacaine (Fig. 3E) groups, only the PR showed severe injury. In the $0.48 \mu \mathrm{L} \cdot \mathrm{g}^{-1}$ procaine (Fig. $3 \mathrm{C}$ ) and $0.48 \mu \mathrm{L} \cdot \mathrm{g}^{-1}$ levobupivacaine (Fig. 3D) groups, both the PR and FC of the PC showed severe damage. group showed a significantly faster recovery than the ropivacaine and levobupivacaine groups $(P=0.001, \quad P=0.041$, respectively $)$ $(P<0.001$ at each level). There was no significant difference in the recovery time between the levobupivacaine and ropivacaine groups $(P=0.94)$. When the concentration was increased to $0.48 \mu \mathrm{L} \cdot \mathrm{g}^{-1} \mathrm{BW}(\mathrm{C})$, rats injected with procaine had a slower recovery than rats injected with ropivacaine $(P=0.054)$ but a faster recovery than rats injected with levobupivacaine, albeit an insignificant difference $(P=0.86)$

In a comparison between normal myelin sheath structure and PR areas with mild injury, electron microscopic examination showed that axonal degeneration was associated with the disappearance of mitochondria, neurofilaments, and prominent microtubules in the axoplasm (Fig. 4B). However, both axonal and myelin degeneration was observed in PR areas with severe injury (Fig. 4C). Thus, these lesions could be characterized by axonal degeneration. The light and electron microscopic findings indicated that neurotoxic lesions induced by procaine, levobupivacaine, and ropivacaine start in the PR entry zone and then extend into the $\mathrm{FC}$ via Wallerian degeneration.

\section{Discussion}

In our previous study using the same protocol, we reported the induction of histological lesions by bupivacaine, mepivacaine, and prilocaine (each at eight times), ${ }^{11}$ lidocaine (3.7 times), ${ }^{9}$ and tetracaine (four times) ${ }^{10}$ higher than their clinical respective concentrations. In the present study, the concentration experiment indicated that procaine, levobupivacaine, and ropivacaine did not induce lesions even when used at ten times the clinical concentrations, suggesting that these three agents are less toxic than the drugs tested previously. We also compared these drugs at larger doses in the volume experiment to estimate the area of neuronal damage which could lead to clinical 
Table 3 Histological injury score in the volume experiment

\begin{tabular}{|c|c|c|c|c|c|}
\hline & $n$ of subjects & $n$ of injury (\%) & $P$ value & Injury score & $P$ value* \\
\hline $0.12 \mu \mathrm{L} \cdot \mathrm{g}^{-1}$ & & & N.D. & & N.D. \\
\hline control & 5 & $0(0)$ & & $0(0-0)$ & \\
\hline $6 \%$ procaine & 6 & $0(0)$ & & $0(0-0)$ & \\
\hline $6 \%$ levobupivacaine & 6 & $0(0)$ & & $0(0-0)$ & \\
\hline $6 \%$ ropivacaine & 6 & $0(0)$ & & $0(0-0)$ & \\
\hline $0.24 \mu \mathrm{L} \cdot \mathrm{g}^{-1}$ & & & $>0.05$ & & $0.089 *$ \\
\hline control & 5 & $0(0)$ & & $0(0-0)$ & \\
\hline $6 \%$ procaine & 6 & $2(33.3)$ & & $0(0-8)$ & \\
\hline $6 \%$ levobupivacaine & 7 & $0(0)$ & & $0(0-0)$ & \\
\hline $6 \%$ ropivacaine & 6 & $0(0)$ & & $0(0-0)$ & \\
\hline $0.48 \mu \mathrm{L} \cdot \mathrm{g}^{-1}$ & & & 0.034 & & $0.001 *$ \\
\hline control & 5 & $0(0)$ & & $0(0-0)$ & \\
\hline $6 \%$ procaine & 6 & $6(100)$ & & $10(10-10)$ & $0.006^{\dagger}$ \\
\hline $6 \%$ levobupivacaine & 6 & $4(66.7)$ & & $8(0-10)$ & $0.014^{\dagger}$ \\
\hline $6 \%$ ropivacaine & 6 & $1(16.7)$ & $0.029^{\#}$ & $0(0-1)$ & \\
\hline
\end{tabular}

Injury score represents the sum of D-score plus S-scores of posterior root and posterior column and is expressed as median (minimum maximum). N.D. = not determined; $\uparrow=$ among the drug groups at each volume (by Fisher's exact test); \# = between ropivacaine and procaine; $*=$ among the drug groups at each volume (by Kruskal-Wallis $\mathrm{H}$ test); $\dagger=$ between procaine, levobupivacaine $v s$ ropivacaine (by post-hoc test, Mann-Whitney $U$ test); $\$=$ injury score significantly higher in procaine and levobupivacaine $v s$ control $(P=0.008$ and $P=0.007$, respectively)
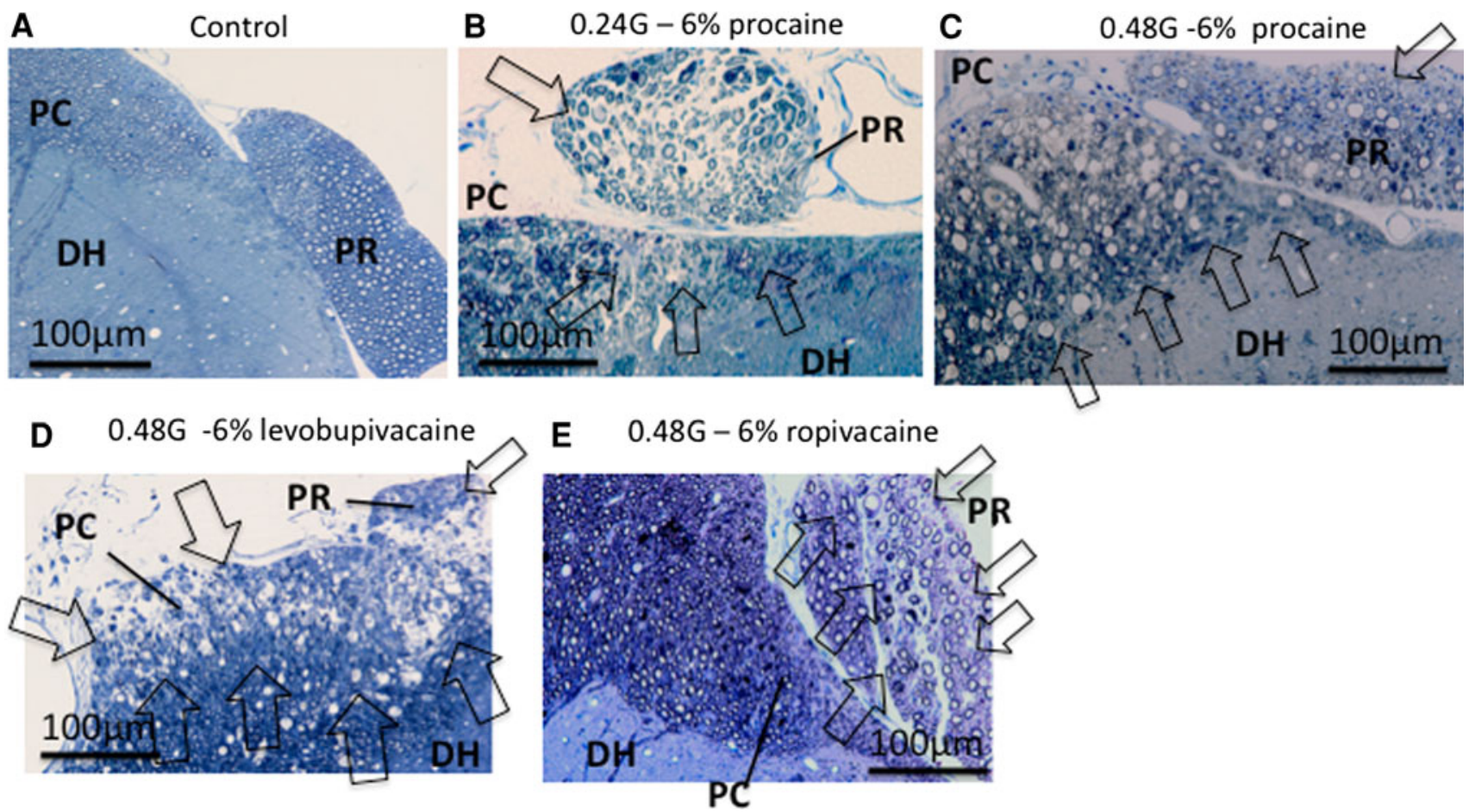

Fig. 3 Light microscopic findings of the posterior root (PR) and posterior white matter column (PC). $\mathrm{A}=$ control (distilled water); $\mathrm{B}=6 \%$ procaine $0.24 \mu \mathrm{L} \cdot \mathrm{g}^{-1} ; \mathrm{C}=6 \%$ procaine $0.48 \mu \mathrm{L} \cdot \mathrm{g}^{-1}$; $\mathrm{D}=6 \%$ levobupivacaine $0.48 \mu \mathrm{L} \cdot \mathrm{g}^{-1} ; \quad \mathrm{E}=6 \%$ ropivacaine $0.48 \mu \mathrm{L} \cdot \mathrm{g}^{-1}$. Arrows show histological lesions. Histological abnormalities were observed only in the posterior root (PR) and posterior column (PC) of rats injected with the three anesthetic agents (B-E), but not in the control rats (A). Histological damage was severe in PR with $6 \%$ procaine $0.24 \mu \mathrm{L} \cdot \mathrm{g}^{-1}$ (B) and with $6 \%$ ropivacaine $0.48 \mu \mathrm{L} \cdot \mathrm{g}^{-1}$ (E). The severity of histological damage in the PR was similar to that in the $\mathrm{PC}$ with $6 \%$ procaine $0.48 \mu \mathrm{L} \cdot \mathrm{g}^{-1}$ (C) and with $6 \%$ levobupivacaine $0.48 \mu \mathrm{L} \cdot \mathrm{g}^{-1}(\mathrm{D}) . \mathrm{DH}=$ dorsal horn $($ Magnification $\times 200$ ) 


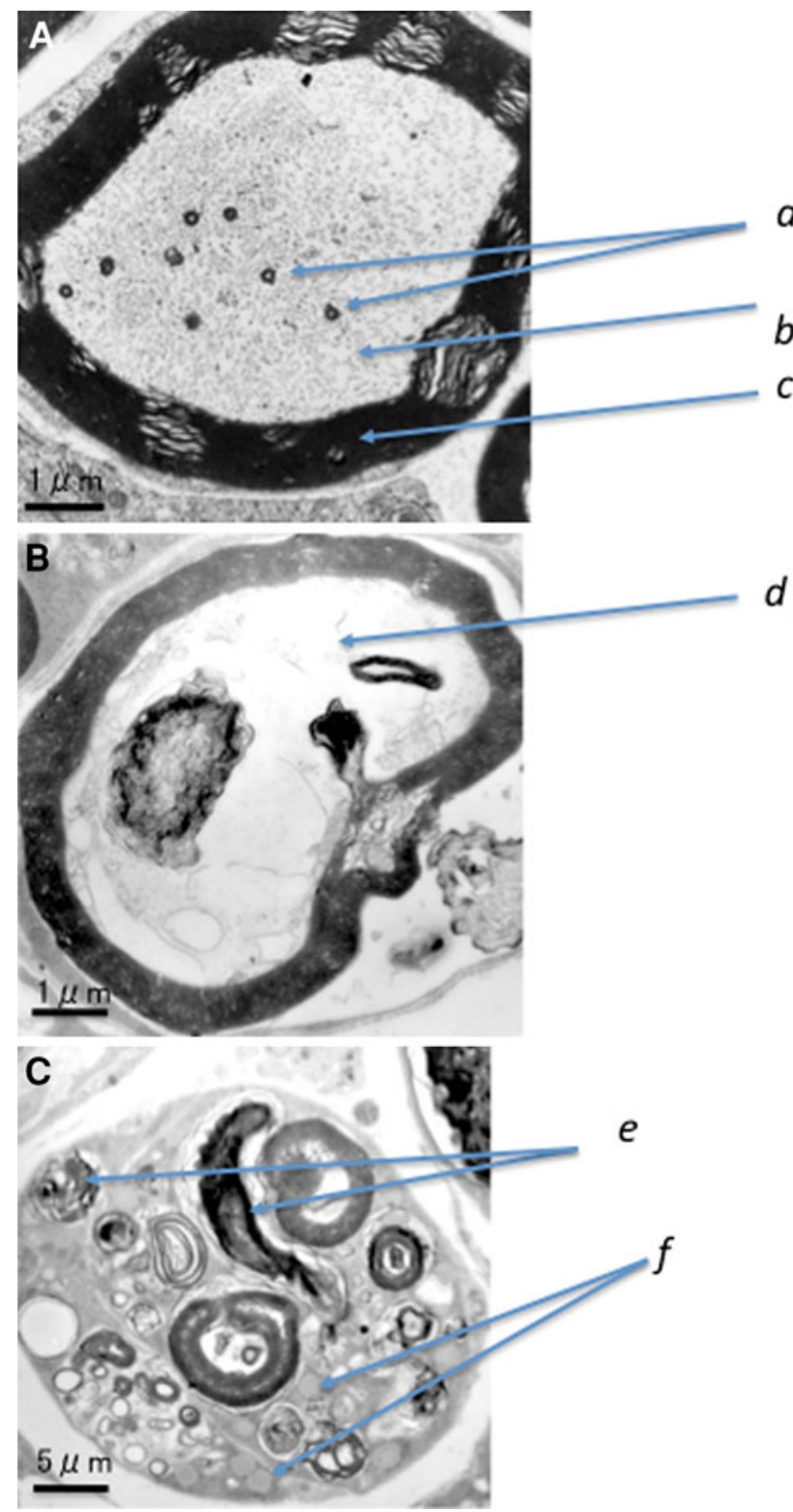

Fig. 4 Electron microscopic findings in the posterior roots. (A) control $=$ distilled water $($ magnification $\times 8000)$; $(\mathrm{B})$ body weight (BW) of $6 \%$ levobupivacaine $0.24 \mu \mathrm{L} \cdot \mathrm{g}^{-1}$ - Axonal degeneration is evident by the disappearance of normal structures, such as mitochondria, neurofilaments, and microtubules. However, myelin sheaths appear intact (magnification $\times 8000)$. (C) BW of $6 \%$ levobupivacaine $0.48 \mu \mathrm{L} \cdot \mathrm{g}^{-1}$ (magnification $\times 6000$ ). $a=$ mitochondria; $b=$ neurofilaments and microtubules; $c=$ myelin sheath; $d=$ degenerated axoplasm; $e=$ disruptive products; $f=$ fat deposit

neurological signs based on the cumulative effect and also to determine whether the pathological changes induced by ropivacaine are identical to those induced by other local anesthetics.

Based on the histological and functional findings after considering the potency of the injected drugs, the toxicity ranking was procaine $>$ levobupivacaine $>$ ropivacaine. The only difference between the latter two agents and other local anesthetics is that they are the S-form. The conclusion on toxicity ranking would be the same if procaine had been given in equipotent doses (24\%); however, it predictably caused severe side effects, especially at $0.48 \mu \mathrm{L} \cdot \mathrm{g}^{-1}$. Since ropivacaine is less soluble and solutions at concentrations higher than $6 \%$ could not be prepared, the concentration of all agents was set at $6 \%$.

The average weight of the rats was $300 \mathrm{~g} ; 20 \%$ procaine $0.12 \mu \mathrm{L} \cdot \mathrm{g}^{-1}$ in the concentration experiment and $6 \%$ procaine at 0.24 and $0.48 \mu \mathrm{L} \cdot \mathrm{g}^{-1}$ in the volume experiment were equal to $7.2,4.3$, and $8.6 \mathrm{mg}$ of procaine, respectively. However, $20 \%$ procaine $0.12 \mu \mathrm{L} \cdot \mathrm{g}^{-1}$ induced no histological damage, while $6 \%$ procaine $0.24 \mu \mathrm{L} \cdot \mathrm{g}^{-1}$ was neurotoxic. These results suggest that the higher volume may have a synergistic effect in worsening the neurotoxic effects in small animals.

Our findings are consistent with many studies reporting that S-form anesthetics have less toxicity on the heart and central nervous system than R-form anesthetics, with toxicity ranking being: bupivacaine $>$ levobupivacaine $>$ ropivacaine. ${ }^{4-8,18}$ The toxicity of racemic bupivacaine was only 1.5-2 times greater than that of the S-forms, levobupivacaine and ropivacaine. ${ }^{4,18}$ However, the present study showed that intrathecally administered bupivacaine was at least 4.8 times as neurotoxic as the S-form drugs (5\% bupivacaine $0.12 \mu \mathrm{L} \cdot \mathrm{g}^{-1}$ vs $6 \%$ ropivacaine $0.48 \mu \mathrm{L} \cdot \mathrm{g}^{-1}$ ). This difference may be due to the route of administration. The severity of cardio- and neurotoxicity after intravenous injection is generally judged by the anesthetic dose that induces arrhythmias and convulsions, respectively. Thus, drugs may be delivered indirectly to the original target tissue after dilution in the blood and metabolism. In the present study, a subarachnoid space injection method was utilized, and the results indicated that ropivacaine is safer than bupivacaine.

In a comparative toxicology study on local anesthetics using cultured cells, the neurotoxic effects of lidocaine, bupivacaine, mepivacaine, and ropivacaine were compared using neurons isolated from the dorsal root ganglia of chick embryos. ${ }^{19}$ In these experiments, the $\mathrm{IC}_{50}$ values after exposure to mepivacaine and lidocaine were the highest and lowest, respectively, whereas those of ropivacaine and bupivacaine were similar (lidocaine, $10^{-2.8} \mathrm{M}$; bupivacaine, $10^{-2.6} \mathrm{M}$; mepivacaine, $10^{-1.6} \mathrm{M}$; ropivacaine, $10^{-2.5} \mathrm{M}$ ). Other investigators ${ }^{20}$ also reported the order of neurotoxicity to be: procaine $=$ mepivacaine $<$ ropivacaine $=$ bupivacaine $<$ lidocaine, because procaine and mepivacaine $5 \times 10^{-4} \mathrm{M}$, bupivacaine and ropivacaine $2 \times 10^{-4} \mathrm{M}$, and lidocaine $1 \times 10^{-4} \mathrm{M}$ induced mild collapse of the growth cones and neurites of freshwater snails. However, the potency of each local anesthetic agent was not considered in the above studies. Considering that mepivacaine and procaine have only $25 \%$ of the potency of ropivacaine, both 
studies could be interpreted as showing that ropivacaine is the least toxic anesthetic among those tested.

Other studies examined the neurotoxicity of the S-form local anesthetics histologically. A study by Malinovsky et $a l .^{21}$ indicated that intrathecally administered lidocaine, but not ropivacaine, was neurotoxic (although no lidocainespecific lesions were identified). In contrast, Yamashita et $a .^{22}$ reported ropivacaine-induced vacuolation in the dorsal column in up to $10 \%$ of cases, but no sensory or motor dysfunction, while lidocaine-induced vacuolation of the dorsal column was noted in $50 \%$ or more animals and was associated with marked neurodysfunction. In these two studies using rabbits, lidocaine was more neurotoxic than ropivacaine, although the histological findings representing neurotoxicity were different. In another rat study, ${ }^{23}$ intrathecal administration of racemic bupivacaine (mixture of S- and R-forms), levobupivacaine (S-form), and dextrobupivacaine (R-form) resulted in dorsal column and nerve root impairment, although the site of root impairment (ventral or dorsal) or the link between spinal lesions and the nerve root were not identified. The toxicity levels of three drugs were similar in their studies, different from the present experiments. It is not clear whether continuous infusion using a pump promoted maldistribution of the local anesthetics, for example, accumulation in the cauda equina region ${ }^{24}$ leading to high concentrations in this region which hampered the assessment of the differences in toxicity levels among the injected local anesthetics.

Taken together with our previous studies, the present findings indicate that tetracaine, lidocaine, prilocaine, mepivacaine, bupivacaine, procaine, levobupivacaine, and ropivacaine are neurotoxic causing mainly axonal damage in the PR entry zone with further expansion into the PC. Since the anterior roots and anterior horn cells were intact, sensory dysfunction, not motor dysfunction, should have been dominant in association with these histological findings. Therefore, the hind limb limitation in our rats appears to be caused by sensory impairment associated with PR and PC injury. This finding suggests that various local anesthetics induce similar dominant sensory symptoms, such as transient neurological symptoms (TNS). Transient neurological symptoms were known previously as transient radicular irritation (TRI) because the symptoms were similar to the signs induced by PR irritation. ${ }^{25}$ The term TRI was later changed to TNS due to the lack of evidence implicating the PR as the cause. However, the present results suggest that PR lesions are related to the onset of TNS. Although TNS represent transient symptoms, the deficit itself might not be transient or reversible, although the symptoms may be irreversible in cases of severe injury, as shown here with procaine administration (procaine $0.24 \mu \mathrm{L} \cdot \mathrm{g}^{-1}$ caused a reversible walking deficit, but procaine $0.48 \mu \mathrm{L} \cdot \mathrm{g}^{-1}$ produced irreversible functional loss).

In summary, the S-form intrathecal anesthetic drugs, especially ropivacaine, have lower neurotoxicity than other local anesthetics of the same class. the present study, neurotoxic lesions were induced by intrathecal ropivacaine and levobupivacaine. The lesions appeared first at the entry zone of the PR root and then at the PC by axonal degeneration, which led to the sensory-dominant symptoms.

Acknowledgements The authors thank Setsuko Murase, Mashashi Tsunoda, Yumiko Sugiura, and the staff of the Research Center for Biological Imaging of Kitasato University for their help with these experiments.

Funding This study was supported by departmental funds.

Conflicts of interest None declared.

\section{References}

1. Albright GA. Cardiac arrest following regional anesthesia with etidocaine or bupivacaine. Anesthesiology 1979; 51: 285-7.

2. Zink W, Graf BM. Benefit-risk assessment of ropivacaine in the management of postoperative pain. Drug Saf 2004; 27: 1093-114.

3. Mather LE. Stereochemistry in anaesthetic and analgetic drugs. Minerva Anestesiol 2005; 71: 507-16.

4. Groban L. Central nervous system and cardiac effects from longacting amide local anesthetic toxicity in the intact animal model. Reg Anesth Pain Med 2003; 28: 3-11.

5. Huang YF, Pryor ME, Mather LE, Veering BT. Cardiovascular and central nervous system effects of intravenous levobupivacaine and bupivacaine in sheep. Anesth Analg 1998; 86: 797-804.

6. Knudsen K, Beckman Suurkula M, Blomberg S, Sjovall J, Edvardsson $N$. Central nervous and cardiovascular effects of i.v. infusions of ropivacaine, bupivacaine and placebo in volunteers. Br J Anaesth 1997; 78: 507-14.

7. Groban L, Deal DD, Vernon JC, James RL, Butterworth J. Does local anesthetic stereoselectivity or structure predict myocardial depression in anesthetized canines? Reg Anesth Pain Med 2002; 27: 460-8.

8. Bardsley H, Gristwood R, Baker H, Watson N, Nimmo W. A comparison of the cardiovascular effects of levobupivacaine and rac-bupivacaine following intravenous administration to healthy volunteers. Br J Clin Pharmacol 1998; 46: 245-9.

9. Takenami T, Yagishita S, Asato F, Hoka S. Neurotoxicity of intrathecally administered tetracaine commences at the posterior root near entry into the spinal cord. Reg Anesth Pain Med 2000; 25: 372-9.

10. Takenami T, Yagishita S, Nara Y, Hoka S. Intrathecal mepivacaine and prilocaine are less neurotoxic than lidocaine in a rat intrathecal model. Reg Anesth Pain Med 2004; 29: 446-53.

11. Takenami T, Yagishita S, Murase S, Hiruma H, Kawakami T, Hoka $S$. Neurotoxicity of intrathecally administered bupivacaine involves the posterior roots/posterior white matter and is milder than lidocaine in rats. Reg Anesth Pain Med 2005; 30: 464-72.

12. Takenami T, Yagishita S, Nara Y, et al. Spinal procaine is less neurotoxic than mepivacaine, prilocaine and bupivacaine in rats. Reg Anesth Pain Med 2009; 34: 189-95. 
13. Stoelting RK, Miller RD. Local anesthetics. In: Stoelting RK, Miller RD, editors. Basics of Anesthesia. 4th ed. Philadelphia, PA: Churchill Livingstone; 2000. p. 80-8.

14. Miller RD, Katzung BG. Local anesthetics. In: Katzung BG, editor. Basic and Clinical Pharmacology. 8th ed. New York: Lange Medical Books/McGraw-Hill; 2001. p. 436-45.

15. Liu SS, McDonald SB. Current issues in spinal anesthesia. Anesthesiology 2001; 94: 888-906.

16. Zaric D, Christiansen C, Pace NL, Puniasawadwong Y. Transient neurologic symptoms after spinal anesthesia with lidocaine versus other local anesthetics: a systemic review of randomized, controlled trials. Anesth Analg 2005; 100: 1811-6.

17. Yaksh TL, Rudy TA. Chronic catheterization of the spinal subarachnoid space. Physiol Behav 1976; 77: 1031-6.

18. Casati A, Putzu M. Bupivacaine, levobupivacaine and ropivacaine: are they clinically different? Best Pract Res Clin Anaesthesiol 2005; 19: 247-68.

19. Radwan IA, Saito S, Goto F. The neurotoxicity of local anesthetics on growing neurons: a comparative study of lidocaine, bupivacaine, mepivacaine and ropivacaine. Anesth Analg 2002; 94: $319-24$
20. Kasaba T, Onizuka S, Takasaki M. Procaine and mepivacaine have less toxicity in vitro than other clinically used local anesthetics. Anesth Analg 2003; 97: 85-90.

21. Malinovsky JM, Charles $F$, Baudrimont $M$, et al. Intrathecal ropivacaine in rabbits: pharmacodynamic and neurotoxicologic study. Anesthesiology 2002; 97: 429-35.

22. Yamashita A, Matsumoto M, Matsumoto S, Ito M, Kawai K, Sakabe T. A comparison of the neurotoxic effect on the spinal cord of tetracaine, lidocaine, bupivacaine, and ropivacaine administered intrathecally in rabbits. Anesth Analg 2003; 97: 512-9.

23. Muguruma T, Sakura S, Kirihara $Y$, Saito $Y$. Comparative somatic and visceral antinociception and neurotoxicity of intrathecal bupivacaine, levobupivacaine, and dextrobupivacaine in rats. Anesthesiology 2006; 104: 1249-56.

24. Rigler ML, Drasner K, Krejcie TC, et al. Cauda equina syndrome after continuous spinal anesthesia. Anesth Analg 1991; 72: 27581.

25. Hartric CT. Transient radicular irritation: a misnomer? Anesth Analg 1997; 84: 1392-3. 